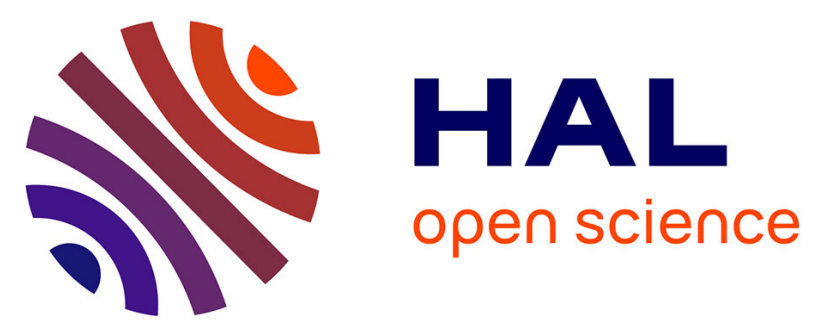

\title{
Tritium absorption/desorption in ITER-like tungsten particles
}

\author{
A. El-Kharbachi, J. Chêne, S. Garcia-Argote, Loic Marchetti, F. Martin, F. \\ Miserque, D. Vrel, M. Redolfi, Veronique Malard, C. Grisolia, et al.
}

\section{- To cite this version:}

A. El-Kharbachi, J. Chêne, S. Garcia-Argote, Loic Marchetti, F. Martin, et al.. Tritium absorption/desorption in ITER-like tungsten particles. International Journal of Hydrogen Energy, 2014, 39 (20), pp.10525-10536. 10.1016/J.IJHYDENE.2014.05.023 • hal-02112327

\section{HAL Id: hal-02112327 \\ https://hal.science/hal-02112327}

Submitted on 4 Jun 2021

HAL is a multi-disciplinary open access archive for the deposit and dissemination of scientific research documents, whether they are published or not. The documents may come from teaching and research institutions in France or abroad, or from public or private research centers.
L'archive ouverte pluridisciplinaire HAL, est destinée au dépôt et à la diffusion de documents scientifiques de niveau recherche, publiés ou non, émanant des établissements d'enseignement et de recherche français ou étrangers, des laboratoires publics ou privés. 


\title{
Tritium absorption/desorption in ITER-like tungsten particles
}

\author{
A. El-Kharbachi ${ }^{a}$, J. Chêne ${ }^{b, *}$, S. Garcia-Argote ${ }^{\text {a }}$, L. Marchetti ${ }^{c}$, F. Martin ${ }^{c}$, F.

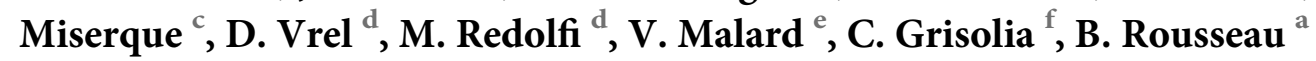 \\ ${ }^{a}$ CEA Saclay, SCBM, iBiTec-S, Tritium Labelling Laboratory, Building 547, PC n 108, 91191 Gif-sur-Yvette, France \\ ${ }^{\text {b }}$ CEA/CNRS, UMR 8587, LAMBE, Université d'Evry Val d'Essonne, 91025 Evry Cedex, France \\ ${ }^{c}$ CEA Saclay, DEN/DPC/SCCME/Laboratoire d'Etude de la Corrosion Aqueuse, F-91191 Gif-sur-Yvette, France

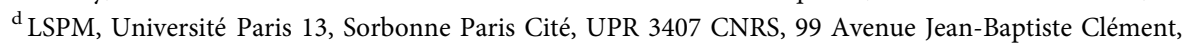 \\ 93430 Villetaneuse, France \\ ${ }^{e}$ CEA, DSV, IBEB, Lab Biochim System Perturb, Bagnols-sur-Cèze F-30207, France \\ ${ }^{\mathrm{f}}$ CEA, IRFM, F-13108 Saint Paul lez Durance, France
}

\begin{abstract}
Tritium retention in plasma facing materials such as tungsten is a major concern for future fusion reactors. During ITER operating mode, the reactor could generate tritiated tungsten dust-like particles which need to be characterized in terms of amount of trapped tritium, tritium source and radiotoxicity. This study is focused on the preparation and character-ization of tungsten particles and on a comparative analysis of tritium absorption/desorp-tion kinetics in these particles and in massive samples. An original gas phase thermal charging procedure was used successfully for tritium incorporation in tungsten powders and massive samples. Much larger tritium amounts are incorporated in $\mathrm{W}$ particles than in massive samples indicating important surface effects on tritium absorption, desorption and trapping in W. Tritium desorption from particles occurred at different temperatures related with different interactions on the particles surface and in the bulk; the tritium behavior in massive samples was also shown to depend on the metal microstructure. According to these experimental results tritium absorption/desorption in $\mathrm{W}$ particles may have important implications on tritium management in ITER reactor.
\end{abstract}

\section{Introduction}

Assessments related to $\mathrm{W}-\mathrm{H}$ system for applications in thermonuclear reactors are in demand with the launch of the ITER international project, the most important international research project on energy. Until now, the walls of the tokamak prototypes consisted mainly of carbon material in which significant trapping of tritium occurred, inducing the release of tritiated carbon particles with activities sometimes higher than $1 \mathrm{GBq} / \mathrm{g}$ [1]. Accidental inhalation of such radioactive particles should thus be harmful for people. More

\footnotetext{
* Corresponding author. CEA, Centre de Saclay-DSV/iBiTec-S/SCBM, Bâtiment 547, 91191 Gif-sur-Yvette Cedex, France. Tel.: +33 (0) 169085493; fax: +33 (0) 169087991.

E-mail address: jacques.chene@cea.fr (J. Chene).
} 
recently, from refractory materials, tungsten has been selected as main suitable plasma facing material in tokamaks and future nuclear fusion reactors [2]. According to its high energy threshold for sputtering [3,4], low ability to hydride formation [5,6], and very low $\mathrm{H}$ solubility level [7-10], tungsten use in reactors could be of great progress for the solving of two major safety issues which are tritium trapping and dust production $[4,11]$.

Nevertheless, during the ${ }^{2} \mathrm{H}-{ }^{3} \mathrm{H}$ plasma as in the ITER project, the reactors could generate tritiated $\mathrm{W}$ dust which need to be characterized and their properties assessed, in terms of amount of trapped tritium and tritium source. Thus their radiotoxicity has to be approached in further investigations. In fact, in case of a loss of vacuum accident (LOVA), the tritiated particles can go through the different protection barriers and filters. Consequently, these particles with a selected size may appear in the working atmosphere, accessible region for the member staff and machineoperators. Hence it is necessary to evaluate their toxicity degree, where the data are lacking as the operating tokamak prototypes with tungsten do not exist yet.

Well before the ITER project attains its operational framework, an experimental study on tungsten particles tritiation needs to be carried out, so that the desorption kinetics of tritium from $\mathrm{W}$ powders could be described and the amount of trapped tritium estimated upon particles size and volume fraction. Existing data on the diffusivity and solubility of hydrogen and its isotopes in bulk metallic tungsten could not be used for such estimation. Indeed, these tokamak W particles-dust usually exhibit very large specific surface area, and their microstructure and surface state may differ from massive $\mathrm{W}$ samples usually used for the determination of hydrogen diffusion data. In particular, both barrier effects of oxide layers and $\mathrm{H}$ trapping on microstructural defects are known to strongly affect the kinetics of $\mathrm{H}$ absorption/ desorption and the residual amount of $\mathrm{H}$ in metals $[12,13]$. Numerous researches have been done recently on the tungsten/hydrogen system to investigate these phenomena (see Ref. [14] for a review); however, all the reported studies in literature deal with massive metallic tungsten. To our knowledge, besides studies on the hydrogen adsorption on tungsten [15], there is no study devoted to the kinetics of tritium absorption/desorption in tungsten powders. Based on the data reported in the literature, the extrapolation at low temperature of most of the diffusive transport parameters of $\mathrm{H}$ and its isotopes in $\mathrm{W}[9-11,16]$, suggests that $\mathrm{H}$ diffusivity, solubility and permeability is very low in $\mathrm{W}$ at room temperature (RT). This is presumably the origin of the large discrepancies reported for $\mathrm{H}$ diffusion data in $\mathrm{W}$ at $\mathrm{RT}$ together with the important experimental difficulties associated with the analysis of very low $\mathrm{H}$ concentrations in W. But isotopic tracing of hydrogen with tritium or deuterium is known to improve the sensitivity in the determination of the diffusive transport and trapping parameters of $\mathrm{H}$ in metals [13,16-22].

For this reason, complementary analysis of the kinetics of tritium or deuterium desorption at $\mathrm{RT}$ in massive $\mathrm{W}$ have been undertaken (i) to improve our knowledge of $\mathrm{H}$ diffusion in $\mathrm{W}$ at $\mathrm{RT}$, (ii) to be used, for comparison purpose, for the assessment of the amounts of tritium that can be reached in finely divided $\mathrm{W}$ particles, (iii) subsequently, in order to manage major fusion reactor issues and safety.

Finally, as a basis for future research on the toxicity of tritiated "ITER like" tungsten particles, this study is focused on the preparation and characterization of tungsten powders and on a comparative analysis of the kinetics of tritium absorption/desorption in these $\mathrm{W}$ particles and in massive samples. The different questions addressed in this study are related to the influence on tritium absorption/ desorption in $\mathrm{W}$ of (i) the presence of oxide films and their barrier effect, (ii) the respective contribution of lattice diffusion and short circuit diffusion along grain boundaries or dislocation networks, (iii) trapping on surface and microstructural defects. A volumetric gas absorption technique was used for tritium insertion at high temperature in the samples and the tritium desorption (amounts and kinetics) was recorded according to different experimental conditions. The comparison of the tritium behavior in $\mathrm{W}$ particles and in massive samples is used to elucidate some of these microstructural and surface phenomena.

\section{Experimental}

\section{Materials characterization}

\section{W particles}

Two lots L1 and L2 of pure tungsten powders (99.9\% purity) were prepared by milling the commercial powders $(99.9 \%$ purity) in ethanol (350 rpm, balls to powder weight ratio 40:1) for $22 \mathrm{~h}$ and $20 \mathrm{~h}$ respectively using tungsten carbide balls and jar. The as milled powders were analyzed by X-ray diffraction (XRD, not shown) and neither crystallized oxide phase nor tungsten carbide impurities from the milling media could be detected.

Using Rietveld refinement, the obtained average crystallites size are 4 and $5 \mathrm{~nm}$ for the two lots respectively with similar micro-strains in both powders which range around $0.3 \%$. The surface area analysis (BET) of the as milled powders provides the following specific surface area (SSA) 15.5 and $7.5 \mathrm{~m}^{2} / \mathrm{g}$ and the calculated particles size, assuming spherical geometry, is 20 and $42 \mathrm{~nm}$ for the two lots L1 and L2 respectively. Planetary ball milling, under the conditions used here, thus produces polycrystalline particles. It should be mentioned however that polycrystallinity is, stricto sensu, due to the presence of high angle grain boundaries (HAGB) that cannot be distinguished from low angle grain boundaries (LAGB) through XRD.

X-ray photoelectron spectroscopy (XPS) was used to investigate the presence of oxide films on the surface of $\mathrm{W}$ particles. XPS analysis was carried out with a Thermofisher Escalab $250 \mathrm{XI}$ spectrometer at the $\mathrm{Al}-\mathrm{K}_{\alpha}$ radiation (Incident energy: $1486.6 \mathrm{eV})$. The binding energy is reported to the carbon $\mathrm{C}_{1 \mathrm{~s}}$ peak $(285.0 \mathrm{eV})$. A solid $\mathrm{W}$ material was used as a reference that was sputtered in-situ with $3 \mathrm{keV}$ Ar ions in order to remove the natural oxide film. Transmission electron microscopy (TEM) micrographs were obtained with a Philips CM12 microscope operating at $100 \mathrm{kV}$. 
Massive specimens

Massive specimens of pure W (99.9\% purity) were taken from a $0.45 \mathrm{~mm}$ thick cold rolled polycrystalline $\mathrm{W}$ sheet. These as received samples (in the following AsR) exhibit a partially recrystallized microstructure with a mean grain size of $4 \mu \mathrm{m}$. Some of these samples were additionally annealed at high temperature $\left(1265^{\circ} \mathrm{C}, 6 \mathrm{~h}, \mathrm{Ar}\right.$ atmosphere) in order to get a fully recrystallized microstructure (in the following Rec samples) with a grain size ranging from 20 to $25 \mu \mathrm{m}$. Scanning electron microscopy (SEM) observations of each microstructure are reported on Fig. 1. AsR samples exhibit a much higher microhardness $\left(642 \mathrm{H}_{v}\right)$ than the recrystallized ones $\left(422 \mathrm{H}_{v}\right)$. This is the consequence of a much higher dislocation density present in the heavily cold rolled AsR microstructure, besides a smaller grain size. Some specimens of another cold rolled "ITER-like" heat (99.97\% nominal purity) were also used for comparison purpose.

These massive specimens were mechanically polished with abrasive papers and mirror finish with $1 \mu \mathrm{m}$ diamond paste in order to remove any preexisting oxide film.

\section{Procedures for tritium charging and analysis}

\section{Tritium charging}

Tritium $\left(\mathrm{T}_{2}\right)$ was purchased from TRITEC (purity 99\%) and stored in its delivery container as intermetallic tritide. $\mathrm{H}_{2}, \mathrm{He}$ and Ar of a high-purity grade (99.999\%) were used as the flow gas where indicated.

It is well known that hydrogen or its isotopes can be loaded into a massive metallic sample by thermal charging, that is the exposure of the specimen to a pressure of hydrogen gas at high temperature providing the absence of barrier effect of oxide films [12]. This requires a two steps approach:

- Firstly the metal surface has to be clean from its oxides and from adsorbed impurities by a first exposure to a hydrogen gas pressure at high temperature,

- Once the oxide film has been removed, di-hydrogen molecules can be dissociated on the metal surface and hydrogen atoms can diffuse into the lattice and the metallurgical defects.

Tritium charging of tungsten powders or massive samples was performed in a glove box using a volumetric gas absorption method in sealed glass vessels at the temperature $477^{\circ} \mathrm{C}$ and under $\mathrm{T}_{2}$ pressure of $0.11 \mathrm{MPa}(1.1 \mathrm{bar})$. Before the tritiation process, all the $\mathrm{W}$ samples were annealed at $475{ }^{\circ} \mathrm{C}$ in a dry hydrogen atmosphere (1.4 bar) in order to reduce preexisting oxide layers.

The vessels were loaded with a known amount of $\mathrm{W}$ powders (few tens of $\mathrm{mg}$ ) or solid (about $1 \mathrm{~g}$ ) and then connected to the pumping system and gas inlet. The samples were first degassed for $20 \mathrm{~h}$ at RT in order to remove any adsorbed impurities. Then, they were given two $\mathrm{H}_{2}$ reduction cycles of $2 \mathrm{~h}$ at $475^{\circ} \mathrm{C}$ for both powder and solid samples. In order to keep the atmosphere dry, each cycle was followed by an outgassing step of $5 \mathrm{~h}$ at RT. Cold traps located near the sample were used to remove any water vapor from the atmosphere. The small glass vial containing deoxidized $\mathrm{W}$ was then loaded with tritium at a pressure of $p\left({ }^{3} \mathrm{H}_{2}\right)=450$ mbar and sealed in the glove box. It was then heated at $477^{\circ} \mathrm{C}$ for $3 \mathrm{~h}$ under a pressure of $1.1 \mathrm{bar}$ of tritium gas and then quenched at the liquid nitrogen temperature to avoid any tritium desorption from the charged samples. According to $\mathrm{H}$ diffusion data in $\mathrm{W}[9-11,16]$ and the specimens geometry, these charging conditions are expected to allow a tritium saturation of both particles and massive samples. Two different tritium enrichment ratio $k={ }^{3} \mathrm{H} /$ $\left({ }^{3} \mathrm{H}+{ }^{1} \mathrm{H}\right)=1$ or $4 \times 10^{-5}$, where used for the preparation of tritiated samples.

The same method, in which tritium was replaced by deuterium gas $(k=1)$ was applied in order to produce deuterated samples.

Procedure for the determination of the kinetics of ${ }^{3} \mathrm{H}$ desorption at RT

ITER-like particles or massive samples with a large enrichment ratio $(\mathrm{k}=1)$. Desorption kinetics were determined after each tritium charging by exposing the samples (powder or solid) to air or argon flow ( $500 \mathrm{ml} / \mathrm{min}$ ) for several days at RT until reaching a plateau in the cumulated amount of desorbed tritium. The outlet flow connected to a tritium analyzer (MARC 7000, SDEC France 2010) is composed of 4
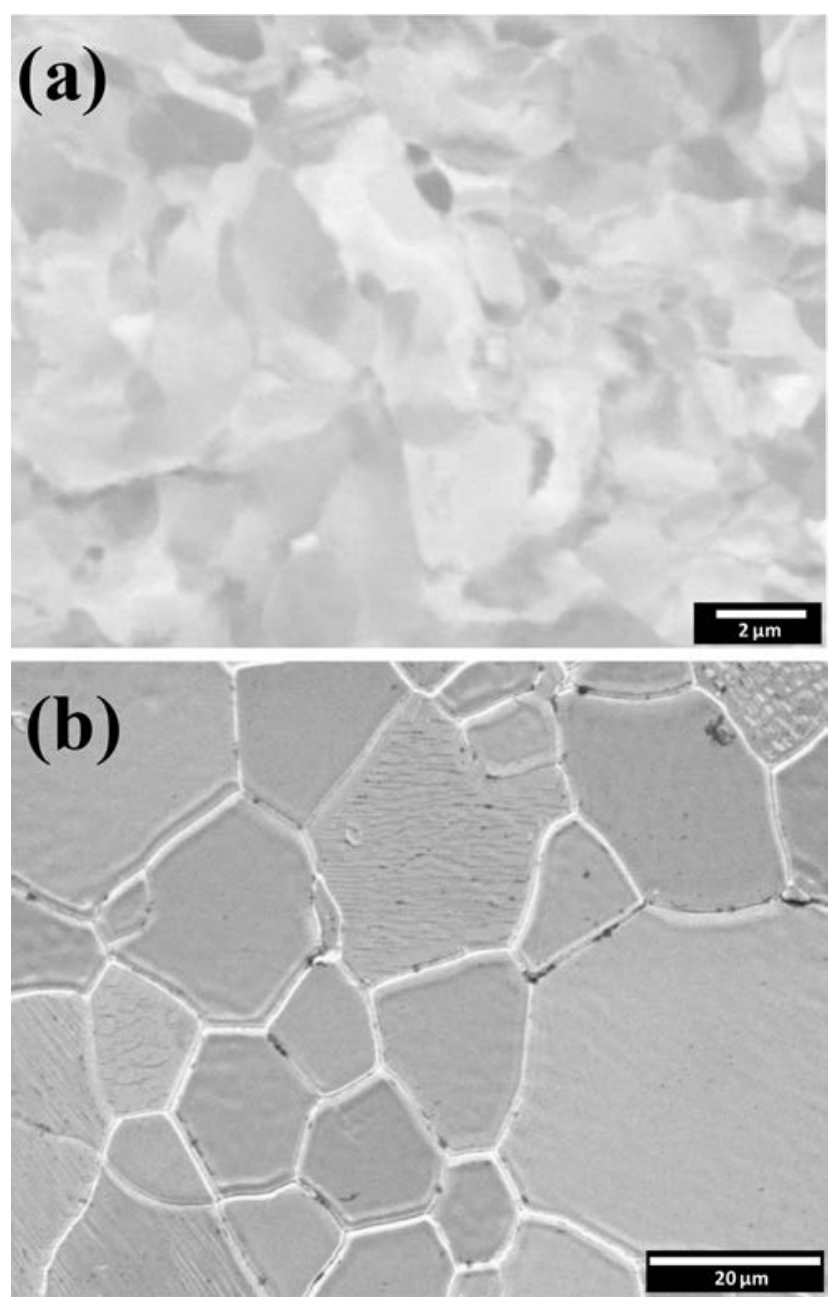

Fig. 1 - SEM observations of the microstructure of massive W samples a) as $R$ specimen, b) Rec specimen. 
bubbler flasks in series (Fig. 2). The two first flasks allow the trapping of tritiated water (called HTO in the following whatever the existence of $\mathrm{HTO}$ or $\mathrm{T}_{2} \mathrm{O}$ species) released in the carrying gas. The flow goes then through an oxidation furnace with a Pd-catalyst for the oxidation of tritium gas into tritiated water which is trapped again in the two next flasks. Tritium in the gaseous form will be called HT whatever the existence of HT or $\mathrm{T}_{2}$ species. The accumulated tritium is tracked by liquid scintillation counting at each time period depending on the desorption kinetic evolution.

The remaining tritium concentration in ITER like particles was determined by liquid scintillation counting after dissolving small amounts (few $\mathrm{mg}$ ) of tritiated powder in water peroxide (30\%) without additional dilution ( $1 \mathrm{mg} / \mathrm{ml})$. It was found that the dissolution is complete within 4 days with stirring periods. Desorption at high-T (up to $800^{\circ} \mathrm{C}$ ) was used for the determination of the remaining tritium in massive samples.

Massive samples with a low enrichment ratio for liquid scintillation counting $(\mathrm{k}<<1)$. A procedure for liquid scintillation counting of solid samples was used for a precise determination of the first step of tritium desorption at RT from massive samples. This procedure allows a continuous recording of the time dependence of the cumulated amount of tritium released from the specimen in the liquid scintillation cocktail. According to the very high sensitivity of this technique (LSC-SS technique) described in detail elsewhere [13], the samples are charged in a tritiated atmosphere with a very low $k$ value $\left(k=4 \times 10^{-5}\right)$.
Thermal desorption analysis

The total or residual amount of tritium in tungsten particles and massive samples was measured by thermal desorption. Two different procedures were used for this purpose.

High temperature desorption tests were conducted by means of the equipment sketched on Fig. 2. A home made silica crucible with entry and exit connections for helium flow $(50 \mathrm{ml} / \mathrm{min}$ ) employed as gas vector was used for desorbing the samples at variable temperatures. The temperature inside the crucible was monitored using a $\mathrm{K}$-type thermocouple and the temperature gradient was found to be less than $1^{\circ} \mathrm{C}$. The downstream outlet is connected to a tritium analyzer. The crucible is placed in the furnace and submitted either to isothermal stages with regular step increase of the temperature in agreement with the reach of a stationary state in the desorption signal, or to a linear temperature ramp $\left(2.5\right.$ or $\left.5{ }^{\circ} \mathrm{C} \mathrm{min}^{-1}\right)$ that is programmed from RT to $800{ }^{\circ} \mathrm{C}$. Samples are then taken for analysis after periodic time steps (5 or $10 \mathrm{~min}$ ).

TDS experiments were also conducted on deuterated samples exposed to a heating cycle in a furnace maintained under high vacuum $\left(10^{-7}\right.$ mbar $)$ thanks to continuous turbomolecular pumping. During these experiments, the temperature of the samples ranges from RT to $800{ }^{\circ} \mathrm{C}$ with a heating rate of $5{ }^{\circ} \mathrm{C} \mathrm{min}^{-1}$. The signals associated with the flux of deuterated species ( $\mathrm{HD}, \mathrm{D}_{2}, \mathrm{HDO}$ and $\mathrm{D}_{2} \mathrm{O}$ ) that desorb from the sample during heating are continuously detected and recorded with a mass spectrometer. The signal recorded for each deuterated species is corrected from the associated background that is measured during a twin experiment involving the sole sample holder.

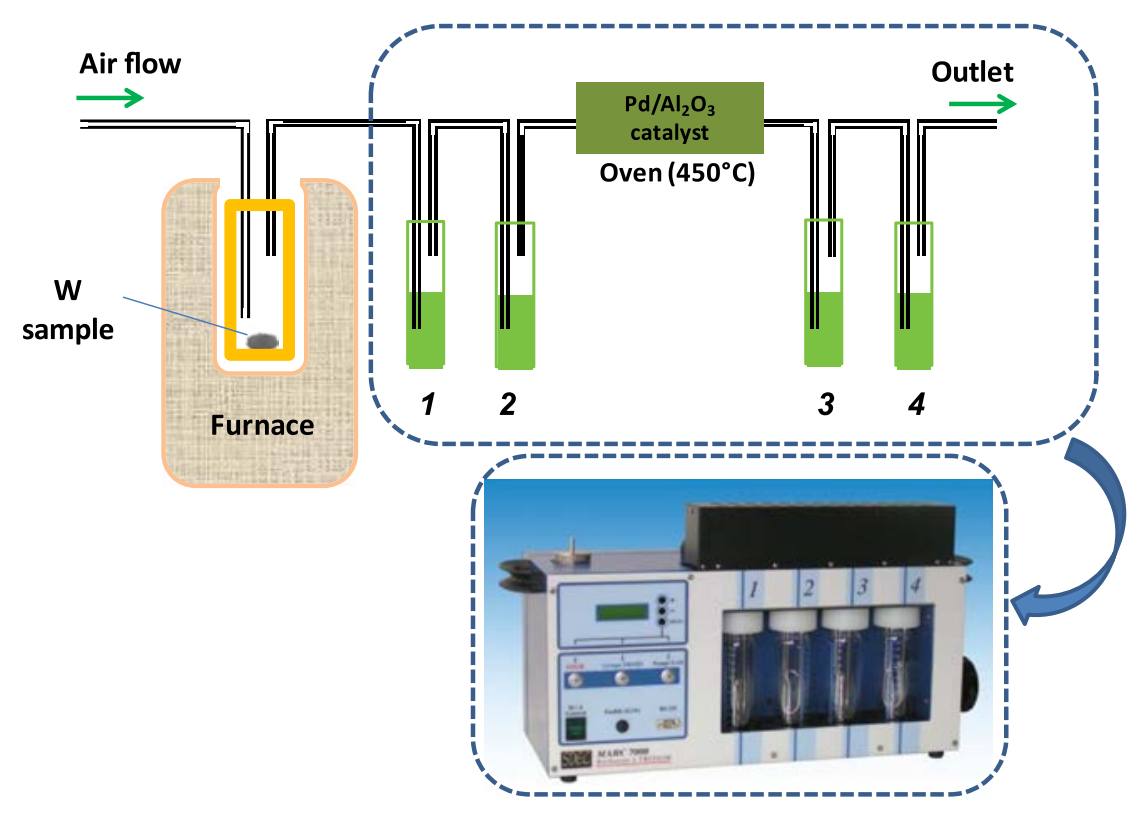

Fig. 2 - Sketch of the equipment used for high-T isothermal desorption: W samples that contain both HTO and HT are heated in a furnace under ambient air flow. Tritiated water vapor formed is trapped in the first two feeding bottles. To trap the tritium gas, an oxidation reaction is performed in the oven by a catalyst $\left(\mathrm{Pd} / \mathrm{Al}_{2} \mathrm{O}_{3}\right)$ which oxidizes HT to HTO. This tritiated water is then trapped in the feeding bottles $n$ \& \& . After a given time, the quantity of tritiated water is determined by liquid scintillation counting. 


\section{Results}

Tritium absorption/desorption in "ITER like" tungsten particles

Tungsten particles were first given a reduction anneal in $\mathrm{H}_{2}$ followed by tritium thermal charging in the conditions reported in $\S 2.2 .1$. The efficiency of the reduction anneal was checked by XPS analysis. The incorporation of tritium into the particles was assessed by several methods. Firstly qualitatively, by introducing few particles of $\mathrm{W}$ into scintillation liquid and measuring the presence of tritium. Secondly quantitatively, by dissolving a known quantity of particles into a solution of hydrogen peroxide and measuring its radioactive content or by measuring at different temperature the tritium desorption from the particles. More than ten different experiments have been done to check reproducibility. We report here the results obtained for two different batches of tungsten particles L1 and L2 having two different SSA, respectively of 15.5 and $7.5 \mathrm{~m}^{2} / \mathrm{g}$, in order to evidence the influence of this parameter.

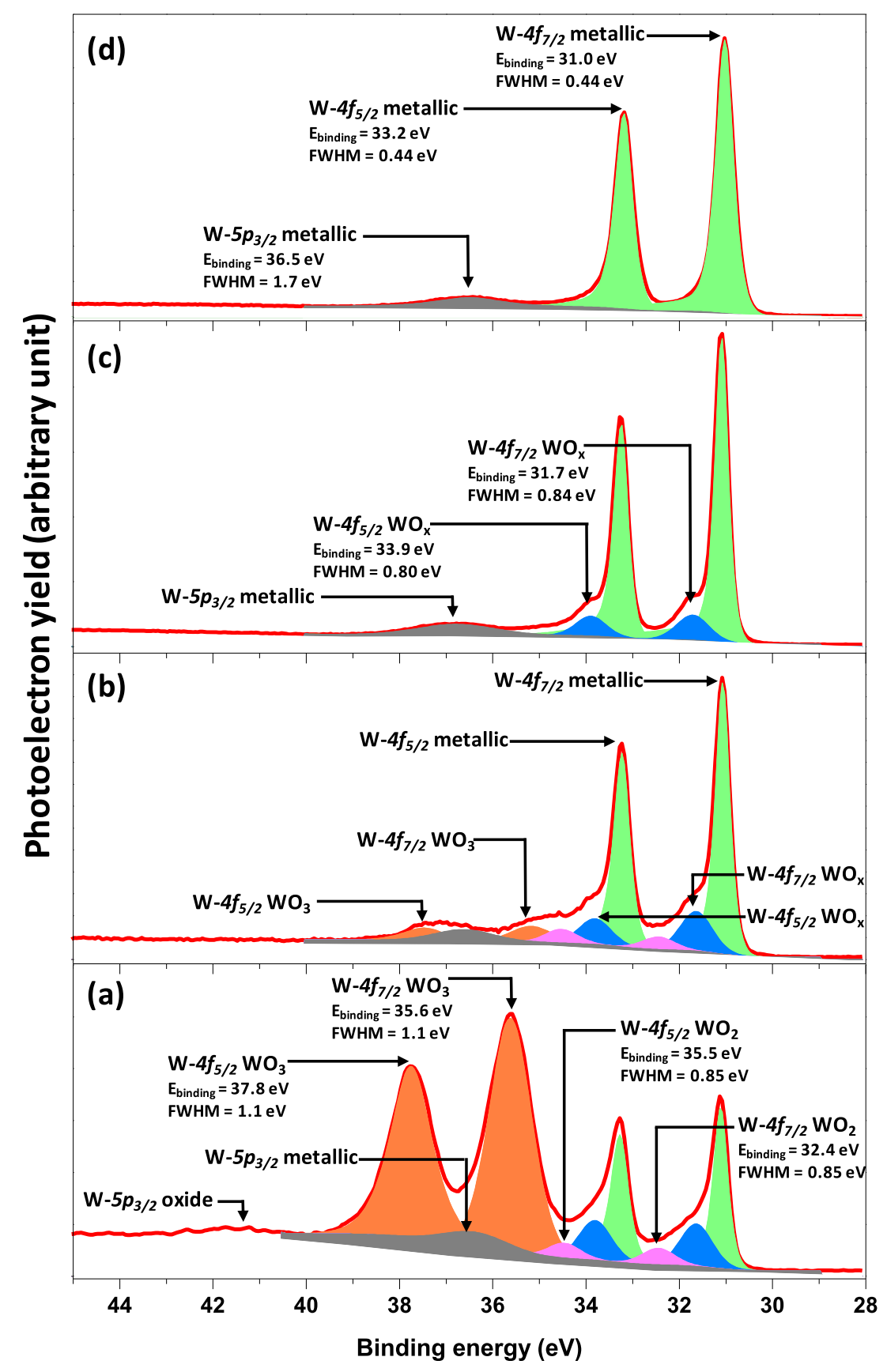

Fig. 3 - W $4 f$ and W $5 p$ photoelectrons spectra regions for (a) as milled powder, (b) after surface reduction of the oxide formed on the milled powder sample, (c) as received polished massive $\mathrm{W}$ sample and (d) after Ar ions etching of the massive $\mathrm{W}$ sample. 

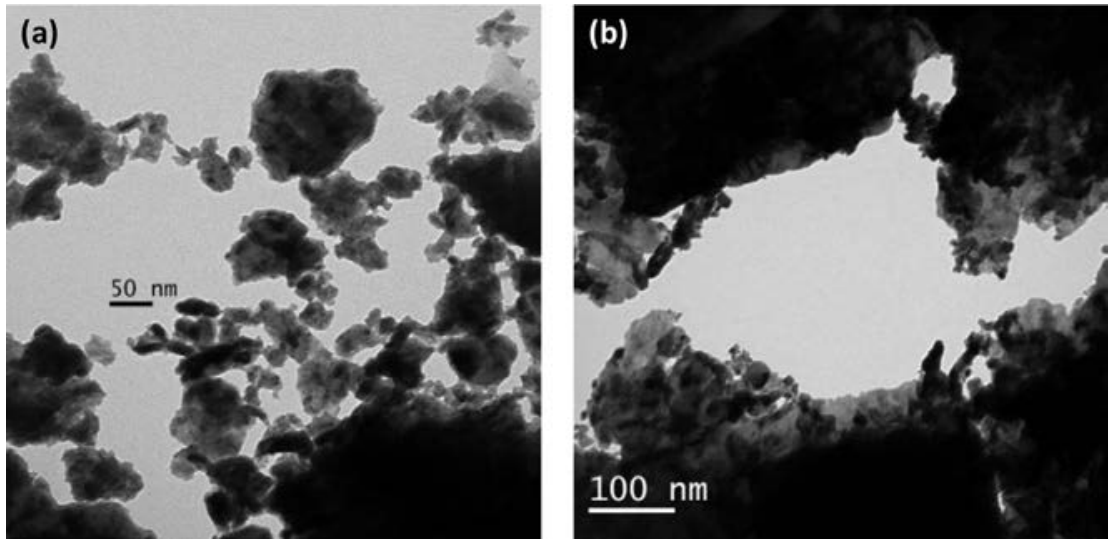

Fig. 4 - TEM micrographs of tungsten particles: (a) as milled powders, (b) after heat treatment at $475{ }^{\circ} \mathrm{C}$ under hydrogen atmosphere.

Reduction of oxide films on tungsten particles

In order to control the efficiency of the reduction process of the oxide layers on $\mathrm{W}$ powders, the surface chemistry of tungsten particles has been characterized by XPS. Fig. 3 shows $\mathrm{W}-4 \mathrm{f}$ and $\mathrm{W}-5 \mathrm{p}$ core levels spectra recorded on $\mathrm{W}$ samples for different surface preparation conditions. The XPS spectra recorded for tungsten powders before (as milled) and after annealing under $\mathrm{H}_{2}$ atmosphere at $475^{\circ} \mathrm{C}$ are reported in Fig. 3( $a$ and $b$ ) respectively. A polished surface of massive $\mathrm{W}$ sample was also analyzed as received (Fig. 3(c)) and after argon ions sputter cleaning in order to remove the native oxide layer (Fig. 3(d)). The W-4f core levels spectrum obtained on the polished $\mathrm{W}$ surface prior to etching shows two chemical contributions: metallic $W$ found at $31.0 \mathrm{eV}$ and $33.2 \mathrm{eV}$ for $\mathrm{W}-4 f_{7 / 2}$ and $\mathrm{W}-4 f_{5 / 2}$ core levels respectively and two peaks at 31.7 and $33.9 \mathrm{eV}$, which are attributed to the presence of $\mathrm{W}-4 f$ in $\mathrm{WO}_{x}(x<2)$ [23]. The in-situ Ar ions etching of the same sample shows the occurrence of only metallic $\mathrm{W}$ contributions representative of a clean surface and used as a reference to obtain the fitting parameters e.g. FWHM, asymmetry parameters (Fig. 3(d)).

The $\mathrm{W}-4 \mathrm{f}$ core levels signal for the as received milled powders (Fig. 3(a)) revealed the presence of two new contributions at high binding energies side compared to polished $\mathrm{W}$ surface. The major contributions found are centered at 35.6 and $37.8 \mathrm{eV}$ for $\mathrm{W}-4 f_{7 / 2}$ and $\mathrm{W}-4 f_{5 / 2}$ core levels respectively. They were associated with the presence of $\mathrm{WO}_{3}$. In a lower extent, $\mathrm{WO}_{2}$ is found with $4 f_{7 / 2}$ and $4 f_{5 / 2}$ located at $32.4 \mathrm{eV}$ and $35.5 \mathrm{eV}$. Metallic $\mathrm{W}$ and $\mathrm{WO}_{x}$ contributions are also present. The annealing under hydrogen of as received milled $\mathrm{W}$ powders lead to a decrease of the $\mathrm{WO}_{3}$ contributions confirming the powders reduction after the annealing procedure. Moreover, it is expected that very few oxide remains on the surface after the reduction heat treatment according to the very limited presence of oxide observed (Fig. 3(b)) after the air exposure of the reduced $\mathrm{W}$ powders before introduction of the sample in the spectrometer chamber.

As XRD patterns recorded on as milled powders do not exhibit any crystallized oxide phase (cf. $\S 2.1$ ), the oxide may exist in the amorphous state (possibly the hydrated $\mathrm{WO}_{3}$ phase $[24,25])$.

TEM observations of $\mathrm{W}$ particles

According to Fig. 4(a), the as milled powders exhibit a wide range of shape and of particles size $(10-200 \mathrm{~nm})$. These values are statistically in fair agreement with those derived from BET measurements. After annealing at $475{ }^{\circ} \mathrm{C}$ under $\mathrm{H}_{2}$ atmosphere, the massive aspect of some W particles (Fig. 4(b))
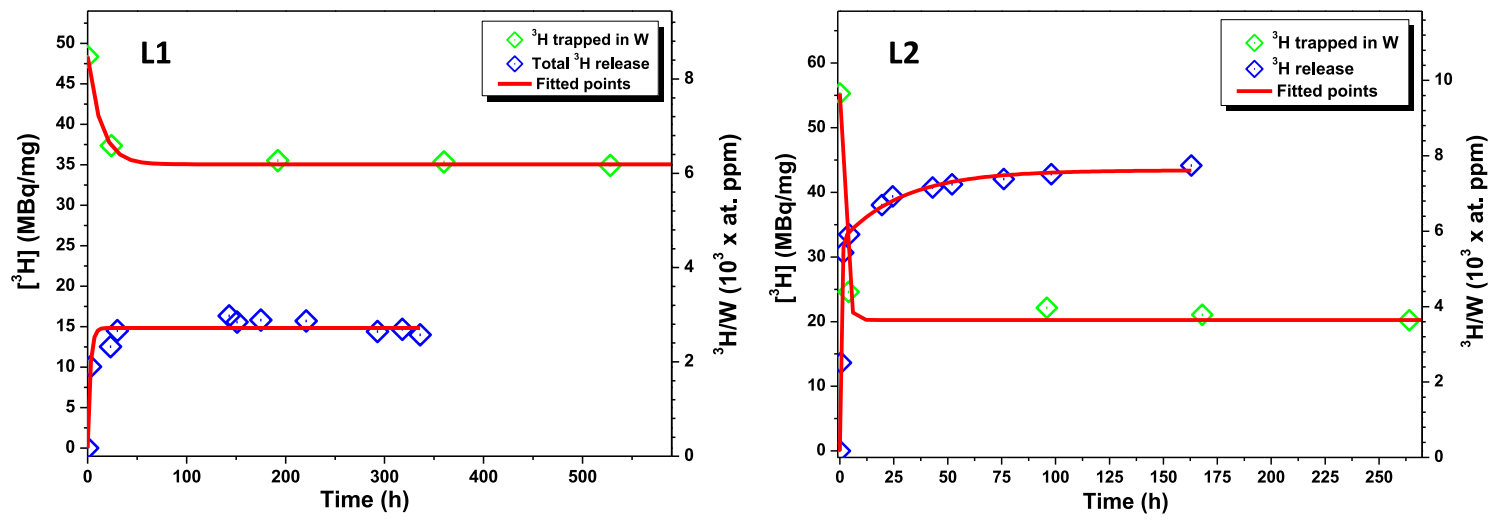

Fig. 5 - Rate of tritium desorption under air and corresponding amount of residual tritium trapped at RT in two tritiated W powders $\mathrm{L} 1$ and $\mathrm{L} 2$ (SSA (L1) $=15.5 \mathrm{~m}^{2} / \mathrm{g}$, SSA (L2) $=7.5 \mathrm{~m}^{2} / \mathrm{g}$ ). 
suggests the existence of the first step of a sintering phenomenon enhanced by the reduction of oxide layers, in agreement with previous observations [14].

Room temperature desorption of tritiated tungsten particles In a first set of experiment the desorption was conducted at RT under air flow using two batch of tungsten particles: L1 and L2.

The desorption kinetics and the evolution of the amount of residual tritium are reported on Fig. 5 for both case showing a desorption plateau reached within 2 days. In both cases most of the tritium desorbs at RT in the form HTO; the fraction of ${ }^{3} \mathrm{H}$ desorbing as tritium gas is less than $5 \%$ under air and almost negligible under Ar. Whereas the origin of HTO was not investigated in details in this study, it is anticipated that it may originate from different sources including (i) isotopic exchange with moisture in the carrying gas or with adsorbed water on W particles or on the walls of the analyzer, (ii) tritium interactions with the hydrated oxide on $\mathrm{W}$ particles or with oxygen gas.

Two tritium concentration levels were measured in the two powders which stabilize at 34 and $19 \mathrm{MBq} / \mathrm{mg}$ for L1 and L2 respectively. These values correspond to very large concentrations (several thousand of at.ppm) when compared to the expected $\mathrm{H}$ solubility in such temperature/pressure conditions (about 1 at.ppm).

It is noteworthy that, after 2 days of RT desorption, the residual amount of tritium in batch $\mathrm{L} 1$ is almost twice more than in batch L2. This may be related to the SSA ratio that is of the order of 2 .

\section{High-T isothermal desorption}

Aiming at the evaluation of residual tritium in these particles after aging at RT and its dependence on the temperature, high-T desorption was carried out up to $1000^{\circ} \mathrm{C}$ under air flow (Fig. 6). As expected from the usual behavior of residual hydrogen in metals, the tritium desorption exhibits a temperature dependence. According to Fig. 6, under isothermal conditions, a significant fraction of tritium (about 30\%) desorbed at $200{ }^{\circ} \mathrm{C}$ whereas most of the residual tritium would be released between 300 and $500{ }^{\circ} \mathrm{C}$. Moreover, above $500{ }^{\circ} \mathrm{C}$ the kinetics of tritium desorption does not significantly depend on

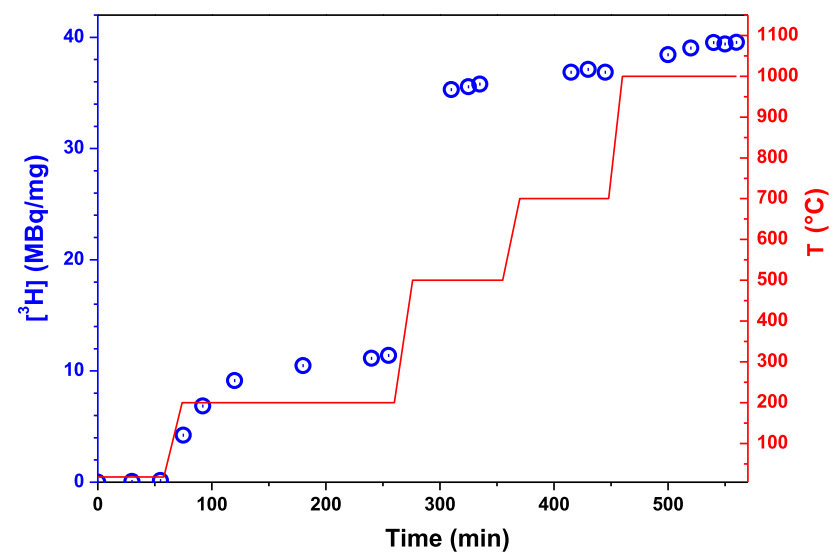

Fig. 6 - High-T isothermal ${ }^{3} \mathrm{H}$ desorption from tritiated L1 powder (after aging) under air flow. Solid line presents the measured real temperature in the crucible. the temperature. After annealing at $1000^{\circ} \mathrm{C}$, the residue in the crucible - mostly in $\mathrm{W}$ oxide form-, was analyzed by liquid scintillation counting after $\mathrm{H}_{2} \mathrm{O}_{2}$ dissolution. A small residual concentration of $0.37 \mathrm{MBq} / \mathrm{mg}$ was obtained indicating that most of the tritium introduced in the particles is released after annealing at $500^{\circ} \mathrm{C}$ under air flow.

\section{Thermal desorption analysis of tritiated and deuterated $\mathrm{W}$ particles}

In order to obtain further information on the behavior of tritium in powders (L2) aged at RT, thermal desorption analysis was performed under a helium atmosphere. The desorbed tritium was systematically evaluated as a function of time with a linear temperature-programmed ramp. Fig. 7 shows the ${ }^{3} \mathrm{H}$ thermal desorption for tritiated $\mathrm{W}$ powders where the desorption of HT and HTO species are plotted separately.

According to the results reported in Fig. 7, a couple of derived thermal-desorption spectra of HT and HTO are shown in Fig. 8, in which two heating rates were experienced. In both cases a large amount of tritium was shown to desorb as HTO species and a small fraction as HT species.

Moreover, two steps may be distinguished on the HT spectra. Desorbed tritium as tritiated water at around $300{ }^{\circ} \mathrm{C}$ shows a relatively broad peak whereas the peak associated with HT is located at a much higher temperature (around $650{ }^{\circ} \mathrm{C}$ ). All the peaks position demonstrates a reasonable heating rate-dependence in agreement with the kinetic models aiming at the determination of the activation energy $[26,27]$. Similar observations were made for isothermal desorption under air flow (Fig. 6): most of tritium desorbs as HTO species and most of the HT species desorbs at high temperature. Moreover, even though the two techniques were carried out in different experimental conditions, considering the differences in isothermal desorption ( $\$ 3.1 .4$ ) and TDS analysis with a temperature ramp, a fair agreement can be found between the temperature of the TDS peak (mean values of 300 and $650{ }^{\circ} \mathrm{C}$, Fig. 8) and the two temperatures of isothermal ${ }^{3} \mathrm{H}$ desorption (200 and $500{ }^{\circ} \mathrm{C}$, Fig. 6).

The observed desorption behavior for tritiated powder sample was extended for a deuterated powder which was prepared in the same conditions i.e. $\mathrm{H}_{2}$ heat treatment and $\mathrm{D}_{2}$ charging. However, unlike tritiated samples, thermal desorption spectra of this specimen were recorded just after charging using a heating rate of $5{ }^{\circ} \mathrm{C} / \mathrm{min}$ and reported in Fig. 9. From RT to more than $300{ }^{\circ} \mathrm{C}$, the fluxes of desorbed $\mathrm{HDO}$ and $\mathrm{D}_{2} \mathrm{O}$ decrease continuously. Then, these two fluxes peak at roughly $360^{\circ} \mathrm{C}$ and finally decrease until $800{ }^{\circ} \mathrm{C}$. On the opposite, fluxes of $\mathrm{D}_{2}$ and $\mathrm{HD}$ species remain weak until they peak at a temperature of $680^{\circ} \mathrm{C}$ where the desorption under vacuum comes close to $\mathrm{HT}$ desorption peak under He atmosphere at the same heating rate for a tritiated powder (Fig. 8). Surprisingly, despite the $k$ ratio of 1 used for the deuterated samples, the signal corresponding to HD is much higher than the one obtained for $\mathrm{D}_{2}$. It may be due to a higher probability of recombination on the surface, thus a higher kinetics of the reaction $\mathrm{H}+\mathrm{D} \rightarrow \mathrm{HD}$ than for $\mathrm{D}+\mathrm{D} \rightarrow \mathrm{D}_{2}$. The presence of a large amount of $\mathrm{H}$ ad-atoms on the surface may originate either from the vacuum (at 

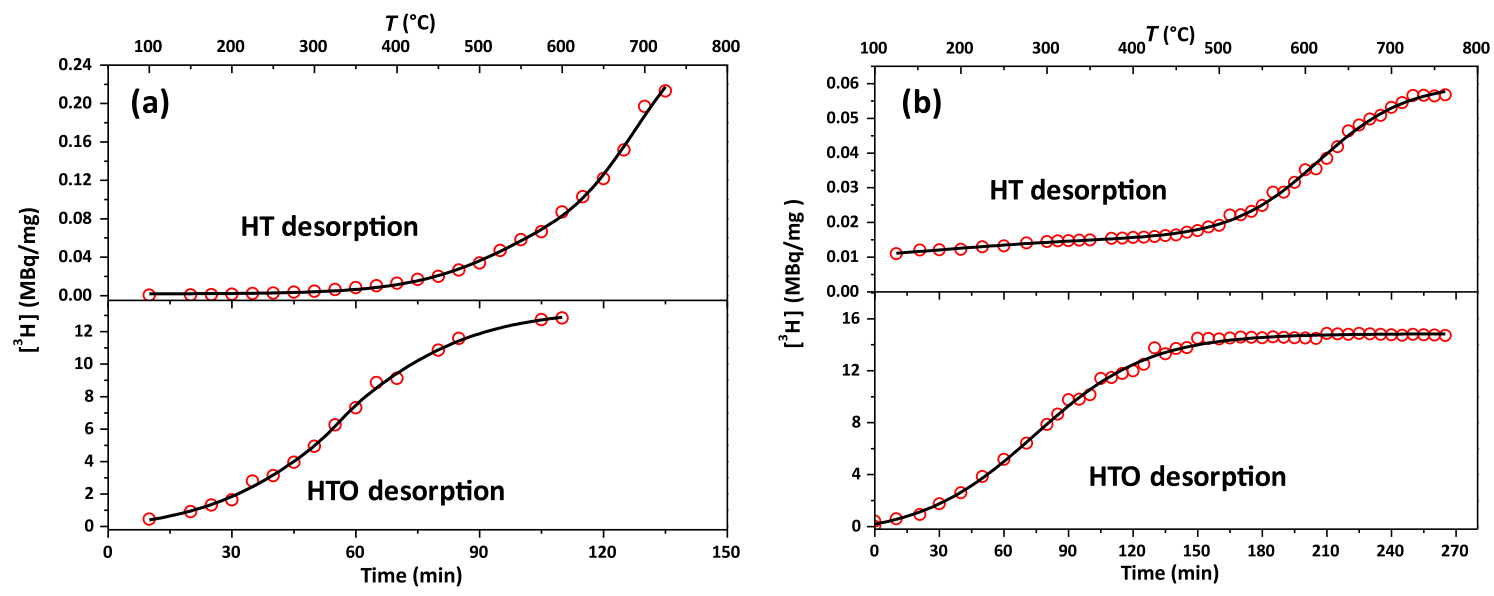

Fig. 7 - Thermal desorption analysis coupled to ex-situ liquid scintillation counting of tritiated aged tungsten powder L2 with two heating rates: (a) $5^{\circ} \mathrm{C} \mathrm{min}^{-1}$ and (b) $2.5^{\circ} \mathrm{C} \mathrm{min}^{-1}$; (circles: Expt. points; solid line: non-linear least squares fitting).

$10^{-7}$ mbar, most of the remaining particles are $\mathrm{H}_{2}$ or $\mathrm{H}_{2} \mathrm{O}$ ) or from the $\mathrm{H}$ absorbed by the bulk material during the reduction process.

It can be also pointed out that the HDO desorption peak at $360{ }^{\circ} \mathrm{C}$ is close in temperature with the HTO desorption peak measured for the same heating rate on the tritiated sample. Nevertheless, the intensities ratios of (i) HD to HDO and (ii) HT to HTO are clearly different in the two types of samples. However, the water vapor partial pressure in the atmosphere in contact with the heated specimen is expected to be much higher under helium flow than under UHV. During the desorption process tritium (or deuterium) may interact at the metal surface with water vapor present in the atmosphere to form HTO (or HDO). According to the high water vapor partial pressure in the TDS experiment devoted to tritium analysis, the amount of collected HTO is expected to be much higher than the amount of HDO recorded in the TDS experiment used for deuterium analysis. For this reason, a direct comparison of the $\mathrm{HTO} / \mathrm{HT}$ ratio with the $\mathrm{HDO} / \mathrm{HD}$ ratio is not straightforward.

\section{Massive tungsten samples}

RT desorption of tritiated massive specimens

Massive samples with $\mathrm{k}=1$. For the sake of comparison, $\mathrm{a}$ massive cold rolled (AsR) W sample was charged with tritium and desorbed at room temperature under air flow with the same procedure as for powder samples (Fig. 10). By comparing W particles (Fig. 5) and massive sample (Fig. 10), the main feature observed is a much larger amount of tritium released from the particles (about 3 orders of magnitude). This is presumably related to the much larger SSA value of the $\mathrm{W}$ particles specimen. The same massive sample was desorbed at high temperature and a fairly low residual concentration of $11.5 \mathrm{MBq} / \mathrm{g}$ (e.g. 2 at.ppm) was measured at $500^{\circ} \mathrm{C}$ under argon flow.

In order to test the influence of the microstructure of massive samples on tritium absorption, another experiment was conducted with three different specimens (Rec, AsR and ITER-like) with the same geometry $\left(0.4 \times 7.5 \times 3.5 \mathrm{~mm}^{3}\right)$. In order to allow a close comparison, they were charged with
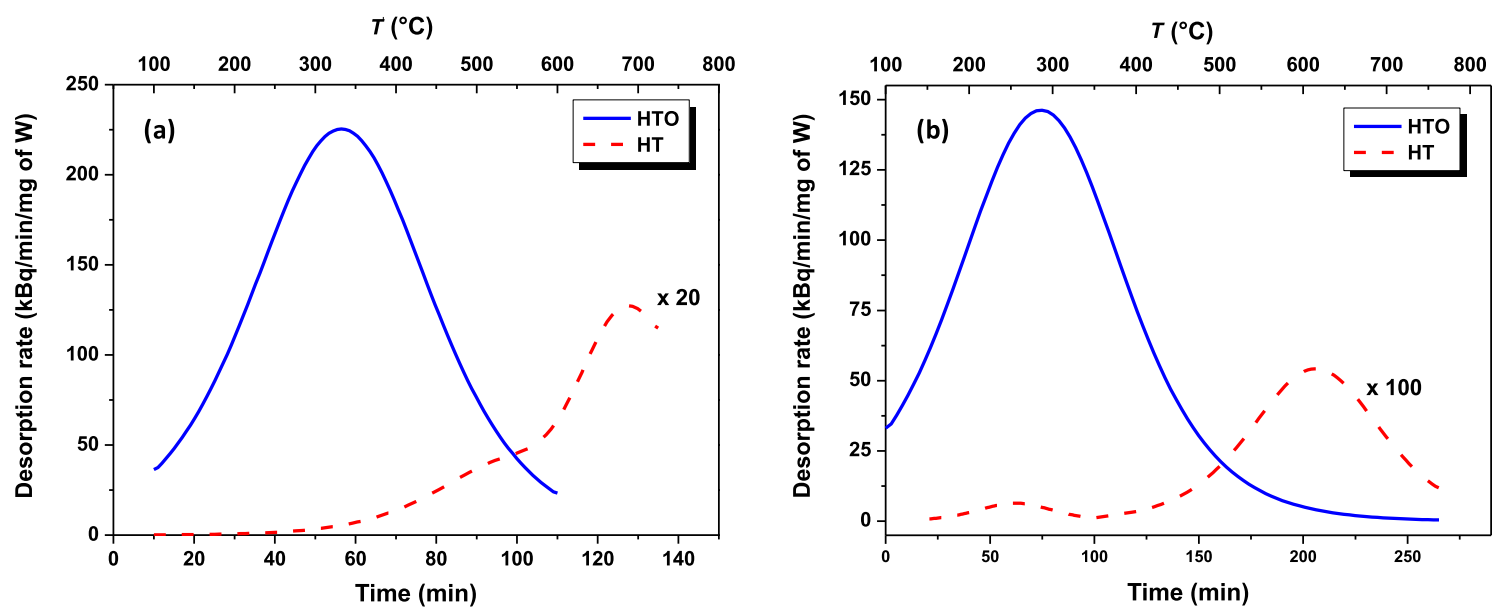

Fig. 8 - Derived desorption rates spectra of tritium and tritiated water gaseous species up to $800{ }^{\circ} \mathrm{C}$ using two heating rates: (a) $5^{\circ} \mathrm{C} \min ^{-1}$ and (b) $2.5^{\circ} \mathrm{C} \min ^{-1}$. 


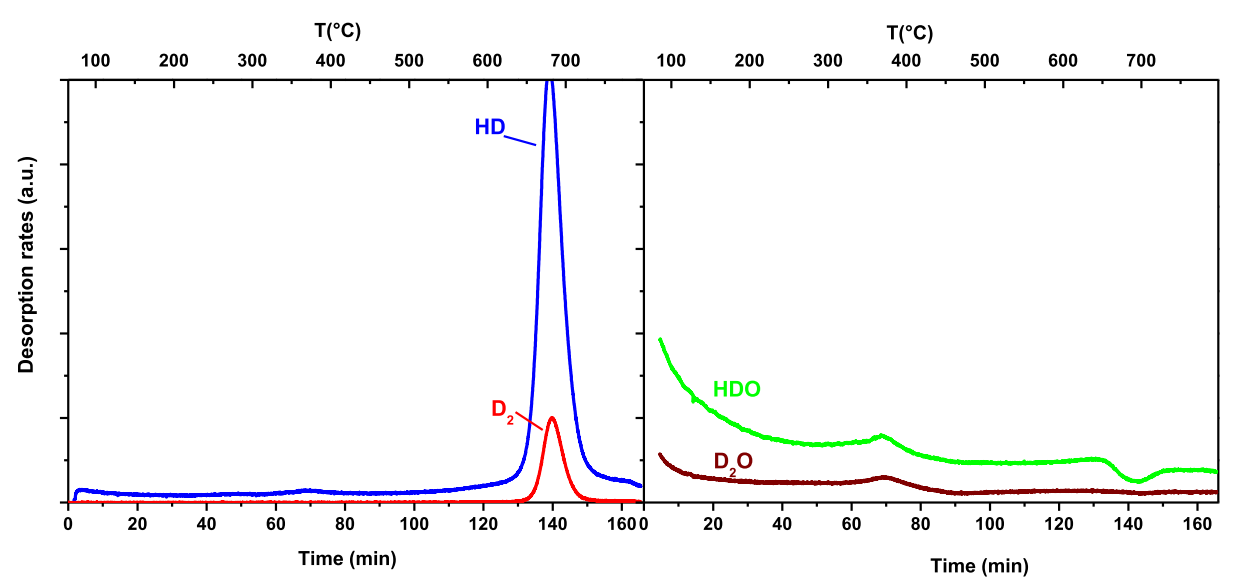

Fig. 9 - Thermodesorption spectra (MS-TDS analysis under UHV, Heating rate $5{ }^{\circ} \mathbf{C} \min ^{-1}$ ) of freshly deuterated powders (without aging) prepared in the same conditions as for the tritiated one. The species are reported in the same arbitrary scale after background subtraction.

tritium $(k=1)$ in the same vessel (same experimental conditions) and stored in liquid nitrogen until measurement of the total amount of absorbed tritium by thermal desorption at $900{ }^{\circ} \mathrm{C}$ under argon flow. The following concentrations $94 \mathrm{MBq} / \mathrm{g}$ (16 at.ppm), $126 \mathrm{MBq} / \mathrm{g}$ (22 at.ppm) and $121 \mathrm{MBq} / \mathrm{g}$ (21 at.ppm) were obtained respectively for Rec, AsR and ITERlike specimens. These results illustrate the capability of the cold rolled samples (AsR and ITER-like) to trap additional tritium on deformation-induced defects as the amount of tritium desorbed from these deformed microstructures is almost 1.5 as much the amount recorded for the recrystallized microstructure. The tritium solubility in pure $\mathrm{W}$ expected for these charging conditions $\left(1.1 \mathrm{bar}, 475^{\circ} \mathrm{C}\right)$ from the literature data [9-11] ranges from less than 0.01 to 2 at.ppm. The much larger measured tritium concentration suggests a significant tritium trapping associated with these charging conditions.

Massive samples with $\mathrm{k}<<1$. Desorption curves recorded for $96 \mathrm{~h}$ at RT with the LSC-SS technique (cf. $\S 2.2 .2 .2$ ) are reported on Fig. 11 for the AsR and Rec massive samples. A desorption plateau is reached within several hours in agreement with the

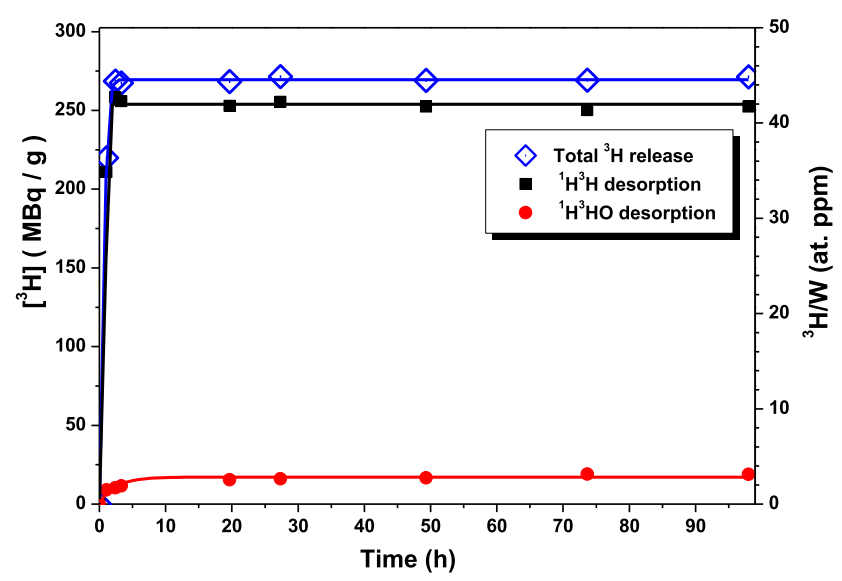

Fig. 10 - Rate of tritium desorption in air at RT from AsR W massive sample. results reported on Figs. 5 and 10. However, both the rate of tritium desorption and the amount of tritium released is strongly dependent on the microstructure of $\mathrm{W}$. In agreement with the results reported in $\S 3.2 .1 .1$, the amount of tritium released from the as received sample is much larger than for the recrystallized specimen presumably as a consequence of tritium trapping in microstructural defects formed in the cold rolled sample. Moreover, taking into account the enrichment ratio $\left(k=4 \times 10^{-5}\right)$ and assuming a negligible isotopic effect on the hydrogen desorption, it is interesting to note that the total amount of tritium released that would be determined by LSCSS for the AsR specimen (approximately $0.1 \mathrm{MBq} / \mathrm{mg}$ ) is comparable to the total amount of desorbed tritium reported on Fig. 10 for a similar AsR massive sample.

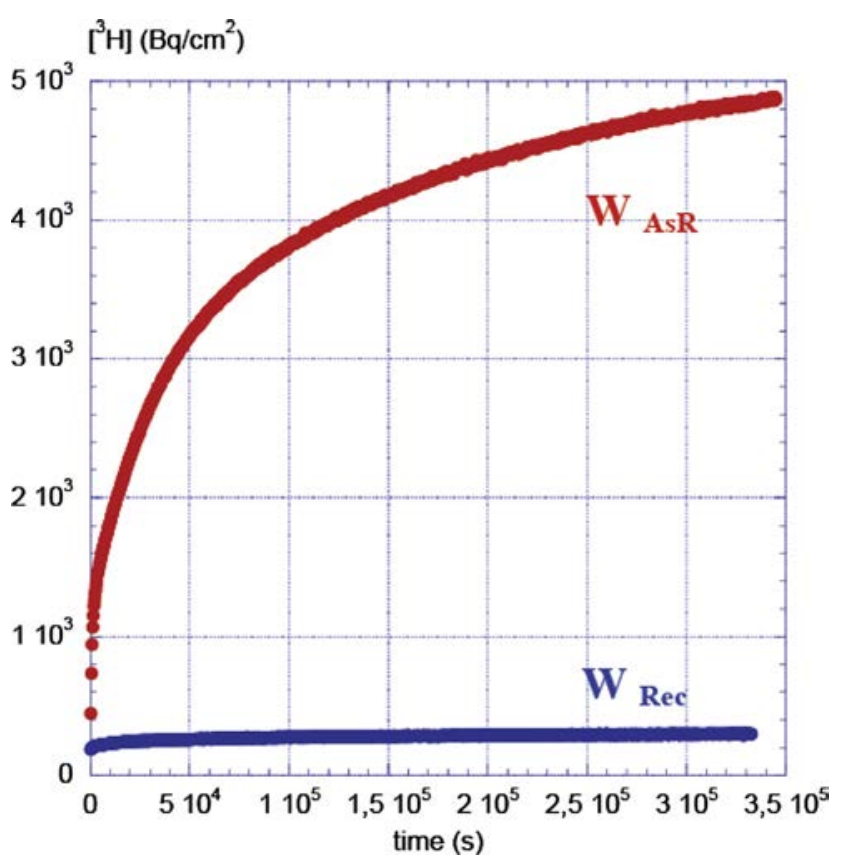

Fig. 11 - Influence of the microstructure on the rate of tritium desorption from massive $\mathrm{W}$ samples. 
On the other hand, the very short desorption transient recorded for the recrystallized sample (Fig. 11) suggests a very fast desorption kinetics which may result from short-circuit diffusion along grain boundaries.

In order to evidence a possible tritium enrichment of the surface of massive samples, the surface activity of each specimen was recorded, after the $96 \mathrm{~h}$ desorption at RT, before and after a slight polishing of the surface used to remove the natural oxide film present on the surface. Surface activities determined at $t=0$ on the desorption spectra reported on Fig. 12 [13], exhibit significant changes associated with the polishing and the metal microstructure. The important drop of the surface activity associated with the removal of a very thin superficial layer (less than $1 \mu \mathrm{m}$ ) is a clear indication of an important tritium enrichment of the close surface. However, taking into account the low value of $k$, the surface activity measured on polished samples demonstrates the presence of significant amount of residual tritium in the bulk of massive samples after aging for $96 \mathrm{~h}$ at RT.

\section{Discussion}

According to the results reported in $\S 3.1$, thermal loading of "ITER like" W particles has been shown to be efficient. A large amount of tritium has been incorporated in the particles. Although the amount of tritium desorbed at RT is difficult to measure precisely due to the fast release of tritium at the beginning of the desorption tests, a significant fraction of tritium (at least several tens of percent) was shown to desorb at room temperature (Fig. 5). Annealing of the particles at high temperature is required to desorb another significant fraction (about 70\%) of tritium presumably trapped on the surface and/ or in the bulk of the particles. According to thermodesorption

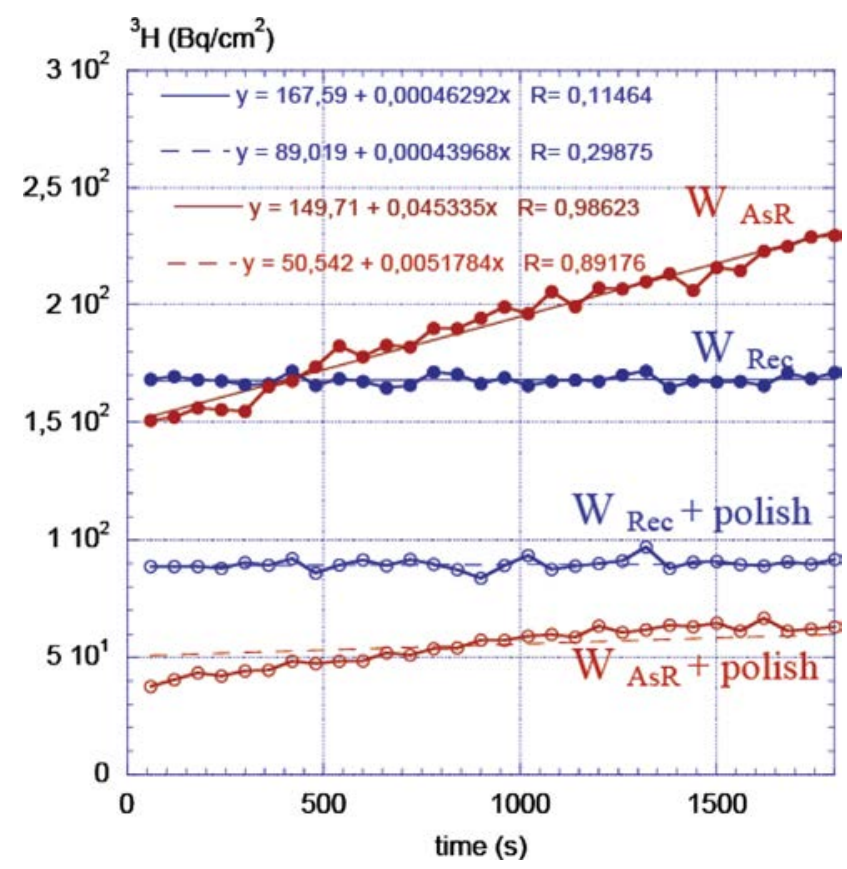

Fig. 12 - Surface activity recorded on massive W samples before and after surface polishing. analysis (Figs. 6-8) part of this residual tritium (about 20\%) is expected to desorb at a moderate temperature $\left(200-300{ }^{\circ} \mathrm{C}\right.$ ) whereas another population of trapped tritium was shown to desorb at a much higher temperature (about $500{ }^{\circ} \mathrm{C}$ ). Additional studies are required to identify more precisely the nature and distribution (near surface, with oxide films and in the bulk) of the different trapping sites interacting with tritium in $\mathrm{W}$ particles. However, according to a previous study on the role of the annealing temperature on tritium desorption from a stainless steel [28], the desorption recorded above $500^{\circ} \mathrm{C}$ on W particles (Figs. 8 and 9) is presumably related to a release of ${ }^{3} \mathrm{H}$ or ${ }^{2} \mathrm{H}$ from the oxide film present on the surface. Moreover, when exposed to a deuterium plasma, the deuterium retention in $\mathrm{WO}_{3}$ oxide film grown on the surface of $\mathrm{W}$ was shown to be much larger than on the oxide free W surface $[29,30]$.

These first quantitative evaluations of the total amount of tritium released from the particles (Figs. 5-8), compared to the amount of tritium incorporated in massive samples (§3.2), indicate that the quantity of ${ }^{3} \mathrm{H}$ incorporated in powders is larger by several order of magnitude than the value which can be anticipated from hydrogen solubility data in massive $\mathrm{W}$ $[9,11]$. This is in favor of an important role of surface effects in the incorporation of ${ }^{3} \mathrm{H}$ by $\mathrm{W}$ particles and confirmed by the raise in the amount of residual tritium with the SSA value of the powder (Fig. 5). These results are in agreement with recent observations of the strong enhancement of tritium retention [31] in the "fuzz" microstructure formed on the surface of W exposed to a helium plasma [32] On the other hand, the results reported for massive sample suggest the existence, for the selected tritium charging conditions, of a significant trapping of ${ }^{3} \mathrm{H}$ in $\mathrm{W}$.

Two main species: HTO and HT were shown to be involved in the process of tritium release from the particles. Tritiated water seems the major species evolving at low temperature whereas the release of tritium gas seems to be preferentially observed at high temperature. However, besides the temperature, the nature of the species involved in the tritium desorption seems to depend on several factor including the atmosphere in contact with the metal surface (air, neutral atmosphere, UHV), the SSA (small particles versus massive samples) and possibly on the nature of the hydrogen isotope (tritium versus deuterium). Whereas additional studies are required to draw precise conclusions, in agreement with a previous investigation on tritium desorption from stainless steels [33], these observations suggest that the nature of the species involved in tritium release from tungsten depends on tritium interactions with oxygen and or water vapor on the surface of W. Such interactions are expected to strongly depend on the SSA, on the presence of oxide films on the surface, and possibly on the activation phenomena associated with the ionization capability of the tritium $\beta$ radiation on the surface [34].

The measure of the surface activity of massive specimens before and after polishing (Fig. 12) gives another evidence of the tritium enrichment of the near surface of $W$. This effect is presumably enhanced by the presence of an oxide film $[29,30]$. However, surface activity measurements also demonstrate the absorption of tritium in the bulk of massive specimens and that a significant amount of tritium remains trapped at RT in the microstructure of $\mathrm{W}$. 
Besides surface effects, the incorporation of tritium in $\mathrm{W}$ and the kinetics of tritium release may strongly depend on the microstructure of the metal. This is clearly evidenced on Fig. 11 where the cold rolled and recrystallized microstructures exhibit a very different behavior, in agreement with previous studies showing the role of strain-induced defects or irradiation-induced defects on deuterium trapping in $\mathrm{W}$ [35-37]. Such microstructural effects have also to be taken into account in the prediction of tritium behavior in "ITER like" W particles.

Finally, when compared to the available solubility data, the large amount of tritium incorporated in $\mathrm{W}$ particles may have important implications both on the tritium inventory in ITER reactor and on the management of the risk assessment associated with tungsten particles. Indeed, according to the total amount of tritium desorbed at high temperature from tritiated W powders (Fig. 6), the amount of tritium trapped in "ITER like" W particles would be approximately $100 \mathrm{~g}$ per ton.

\section{Conclusions}

An original procedure of thermal charging in gas phase has been shown to be successful for the incorporation of tritium in tungsten particles. Different desorption tests were then conducted both at room temperature and high temperature on well characterized "ITER like" W particles and massive samples showing a different behavior of tritium in particles and in massive samples. The following conclusions can be drawn from the experimental results:

(i) A much larger amount of tritium is incorporated in W particles than in massive samples indicating important surface effects on tritium absorption, desorption and trapping in W. Moreover the behavior of tritium in massive samples was also shown to depend on the metal microstructure.

(ii) Tritium evolving from tritiated $\mathrm{W}$ particles was shown to desorb mostly as tritiated water - major component - with minor tritium gas species which occur at different temperatures revealing different types of tritium/tungsten interactions occurring either on the surface or in the bulk of the metal.

(iii) The strong enhancement of tritium absorption/ desorption in $\mathrm{W}$ particles may have important implications on the management of ITER reactor.

(iv) The characterization of tritium absorption/desorption in "ITER-like" tungsten particles is the basis for future research on the toxicity of these particles that could be inhaled in case of accidental contamination.

\section{Acknowledgments}

The authors would like to acknowledge the CEA/DSV (France) for financial support in the frame of "Tuntox" transversal project.
Plansee $\mathrm{GmbH}$ is acknowledged for providing the ITER-like tungsten grade.

The views and opinions expressed herein do not necessarily reflect those of the ITER Organization.

\section{REFERENCES}

[1] Di Pace L, Letellier E, Maubert H, Patel B, Raskob W. Biological hazard issues from potential releases of tritiated dust from ITER. Fusion Eng Des 2008;83:1729-32.

[2] Davis JW, Barabash VR, Makhankov A, Plöchl L, Slattery KT. Assessment of tungsten for use in the ITER plasma facing components. J Nucl Mater 1998;258-263(Part 1):308-12.

[3] Langmuir I. The vapor pressure of metallic tungsten. Phys Rev 1913;2:329-42.

[4] Sakamoto R, Muroga T, Yoshida N. Microstructural evolution induced by low energy hydrogen ion irradiation in tungsten. J Nucl Mater 1995;220-222:819-22.

[5] Garvey JF, Kuppermann A. Observation and analysis of emission spectra of tungsten hydride. J Phys Chem 1988;92:4583-8.

[6] Scheler T, Peng F, Guillaume CL, Howie RT, Ma Y, Gregoryanz E. Nanocrystalline tungsten hydrides at high pressures. Phys Rev B 2013;87:184117.

[7] Mazaev AA, Avarbe RG, Vil'k YN. Hydrogen solubility in tungsten. Izv Akad Nauk USSR Metal 1968;6:233-6.

[8] Frauenfelder R. Solution and diffusion of hydrogen in tungsten. J Vac Sci Technol 1969;6:388-97.

[9] Esteban GA, Perujo A, Sedano LA, Douglas K. Hydrogen isotope diffusive transport parameters in pure polycrystalline tungsten. J Nucl Mater 2001;295:49-56.

[10] Zakharov AP, Sharapov VM, Evko ÉI. Hydrogen permeability of polycrystalline and monocrystalline molybdenum and tungsten. Fiz-Khim Mekh Mater 1975;9:149-53.

[11] Causey RA. Hydrogen isotope retention and recycling in fusion reactor plasma-facing components. J Nucl Mater 2002;300:91-117.

[12] Brass AM, Chêne J, Coudreuse L. Fragilisation des aciers par l’hydrogène: mécanismes. Techniques de l'ingénieur, Matériaux métalliques. Editions T.I; 2000. pp. 1-12. M176.

[13] Chêne J, Brass AM, Trabuc P, Gastaldi O. Role of microstructure and heat treatments on the desorption kinetics of tritium from austenitic stainless steels. J Nucl Mater 2007;360:177-85.

[14] Skinner CH, Haasz AA, Alimov VKH, Bekris N, Causey RA, Clark REH, et al. Recent advances on hydrogen retention in ITER's plasma-facing materials: beryllium, carbon, and tungsten. Fusion Sci Technol 2008;54:891-945.

[15] Frankenburg WG. The adsorption of hydrogen on tungsten1. J Am Chem Soc 1944;66:1827-38.

[16] Ikeda T, Otsuka T, Tanabe T. Determination of hydrogen diffusivity and permeability in $\mathrm{W}$ near room temperature applying a tritium tracer technique. J Nucl Mater 2011;415:S684-97.

[17] Brass AM, Chêne J. Application du deutérium et du tritium à la mesure de la concentration locale en hydrogène dans les métaux en relation avec les risques de fragilisation. Rev Metall/Cah Inf Tech; 1995:1383-97.

[18] Chêne J. Tritium deformation interactions in FCC austenitic steels. Fusion Sci Technol 2008;54:506-9.

[19] Perevezentsev AN, Bell AC, Rivkis LA, Filin VM, Gushin VV, Belyakov MI, et al. Comparative study of the tritium distribution in metals. J Nucl Mater 2008;372:263-76. 
[20] Nakamura H, Shu W, Hayashi T, Nishi M. Tritium permeation study through tungsten and nickel using pure tritium ion beam. J Nucl Mater 2003;313-316:679-84.

[21] Hoshihira T, Otsuka T, Wakabayashi R, Tanabe T. Hydrogen behavior near surface regions in Mo and W studied by tritium tracer technique. J Nucl Mater 2011;417:559-63.

[22] Hino T, Yamauchi Y, Kimura Y, Nishimura K, Ueda Y. Fuel hydrogen retention of tungsten and the reduction by inert gas glow discharges. Fusion Eng Des 2012;87:876-9.

[23] Xie FY, Gong L, Liu X, Tao YT, Zhang WH, Chen SH, et al. XPS studies on surface reduction of tungsten oxide nanowire film by $\mathrm{Ar}^{+}$bombardment. J Electron Spectrosc Relat Phenom 2012;185:112-8.

[24] Deb SK. Optical and photoelectric properties and colour centres in thin films of tungsten oxide. Philos Mag 1973;27:801-22.

[25] Radovan G, Slavko M. The synthesis of tungsten trioxide ge] by dissolution of tungsten in hydrogen peroxide and its transformations during the heat treatment in oxidation and reduction atmospheres. Hem Ind 2011;65:279-86.

[26] Stakebake JL. Thermal desorption study of the surface interactions between water and plutonium dioxide. J Phys Chem 1973;77:581-6.

[27] Hirabayashi T, Saeki M, Tachikawa E. A thermal desorption study of the surface interaction between tritium and type 316 stainless steel. J Nucl Mater 1984;126:38-43.

[28] Lassoued A, Chêne J, Brass AM, Gastaldi O, Trabuc P, Marbach G. Influence of heat treatments on residual tritium amount in tritiated stainless steel waste. Fusion Eng Des 2005;75-79:731-5.
[29] Ogorodnikova OV, Roth J, Mayer M. Deuterium retention in tungsten in dependence of the surface conditions. J Nucl Mater 2003:313-316:469-77.

[30] Alimov VKh. Deuterium retention in pure and mixed plasma facing materials. Phys Scr 2004;T108:46-56.

[31] Yajima M, Shi J, Hatano Y, Saeki T, Kajita S, Ohno N. Tritium retention by tungsten with nano-morphology. In: Proc. 9th Int. Conf. On tritium Science and Technology Oct 24-29 2010 Nara Japan.

[32] Baldwin MJ, Doerner RP. Formation of helium induced nanostructure "fuzz" on various tungsten grades. J Nucl Mater 2010;404:165-73.

[33] Quinlan MJ, Shmayda WT, Lim S, Salnikov S, Chambers Z, Pollock E, et al. Effects of $\mathrm{H}_{2} \mathrm{O}$ and $\mathrm{H}_{2} \mathrm{O}_{2}$ on thermal desorption of tritium from stainless steel. Fusion Sci Technol 2008;54:519-22.

[34] Chapter 6 Bellanger G. Stability of tritiated oxide layer. Corrosion induced by low-energy radionuclides. Amsterdam: Elsevier; 2004. pp. 101-22.

[35] Anderl RA, Holland DF, Longhurst GR, Pawelko RJ, Trybus CL, Sellers CH. Deuterium transport and trapping in polycrystalline tungsten. Fusion Technol 1992;21:745-52.

[36] Alimov VKh, Roth J, Causey RA, Komarov DA, Linsmeier Ch, Wiltner A, et al. Deuterium retention in tungsten exposed to low-energy, high-flux clean and carbon-seeded deuterium plasmas. J Nucl Mater 2008;375:192-201.

[37] Tyburska B, Alimov VKh, Ogorodnikova OV, Ertl K, Schmid K, Roth J. Trapping of permeating deuterium in defect induced at the rear side of tungsten samples. J Nucl Mater 2011;415:S680-3. 